\title{
Expression of Lipoprotein Lipase mRNA and Secretion in Macrophages Isolated from Human Atherosclerotic Aorta
}

\author{
Lillemor Mattsson, Helena Johansson, Malin Ottosson, Göran Bondjers, and Olov Wiklund \\ The Wallenberg Laboratory for Cardiovascular Research, Department of Medicine I, University of Gothenburg, Gothenburg, Sweden
}

\begin{abstract}
The expression of lipoprotein lipase (LPL) mRNA and the LPL activity were studied in macrophages (CD14 positive) from human atherosclerotic tissue. Macrophages were isolated after collagenase digestion by immunomagnetic isolation. About $90 \%$ of the cells were foam cells with oil red $O$ positive lipid droplets. To analyze the mRNA expression, PCR with specific primers for LPL was used. Arterial macrophages were analyzed directly after isolation and the data showed low expression of LPL mRNA when compared with monocyte-derived macrophages. To induce the expression of LPL mRNA in macrophages, PMA was used. When incubating arterial macrophages with PMA for $24 \mathrm{~h}$ we could not detect any increase in LPL mRNA levels. Similarly, the cells secreted very small amounts of LPL even after PMA stimulation. In conclusion, these studies show a very low expression of LPL mRNA in the CD14-positive macrophage-derived foam cells isolated from human atherosclerotic tissue. These data suggest that the CD14-positive cells are a subpopulation of foam cells that express low levels of lipoprotein lipase, and the lipid content could be a major factor for downregulation of LPL. However, the cells were isolated from advanced atherosclerotic lesions, and these findings may not reflect the situation in early fatty streaks. (J. Clin. Invest. 1993. 92:1759-1765.) Key words: polymerase chain reaction - cytokines - foam cells • cell isolation $\bullet$ atherosclerosis
\end{abstract}

\section{Introduction}

Lipid laden cells, foam cells, are a hallmark of the early atherosclerotic lesions. Most of these cells seem to be derived from macrophages (1). Macrophages are best known for their phagocytotic activity but are also secreting cells that produce several biologically active substances such as growth factors, cytokines, and reactive oxygen intermediates. The exact mechanism for foam cell formation has not been settled. Macrophages do not become foam cells when incubated with native LDL but incubation with hypertriglyceridemic VLDL or modified (oxidized, acetylated) LDL has been shown to result in foam cell formation in vitro (2-4). Lipoprotein lipase

Address correspondence to Dr. O. Wiklund, Wallenberg Laboratory, Sahlgren's Hospital, S-413 45 Gothenburg, Sweden.

Received for publication 17 November 1992 and in revised form 6 May 1993.

J. Clin. Invest.

(C) The American Society for Clinical Investigation, Inc.

$0021-9738 / 93 / 10 / 1759 / 07 \$ 2.00$

Volume 92, October 1993, 1759-1765
$(\mathrm{LPL})^{1}$ is responsible for the catabolism of triglyceride-rich lipoproteins, i.e., chylomicrons and VLDLs. LPL enzyme activity has been found in the intima of larger arteries in experimental atherosclerosis $(5,6)$. LPL could create remnants locally in the tissue and increase the cholesterol deposition in the arterial wall. In agreement, studies by Lindquist et al. (7) suggest that triglyceride-rich lipoproteins may contribute to foam cell formation through the local degradation of lipoproteins by lipoprotein lipase, and to the uptake of remnant particles into macrophages. Aviram et al. (8) demonstrated that LPL also can modify LDL so that it is taken up more avidly by cultured macrophages. Another mechanism is proposed by Beisiegel et al. (9). They show that lipoprotein lipase enhances the binding of chylomicrons and $\beta$-VLDL to cells via the LDL receptor-related protein, which could be a mechanism for foam cell formation. In vitro studies show secretion of LPL in monocytederived macrophages (10), mouse peritoneal macrophages, or monocyte-derived cell lines (11-14). In immunohistochemical studies on human plaques Jonasson et al. (15) found no LPL associated with CD14-positive cells. On the other hand, protein was observed in relation to smooth muscle cells. Recently Ylä-Herttuala et al. (16) found, by in situ hybridization and immunocytochemistry, that a subfraction of lesion macrophages detected with a mAb against human macrophages (HAM-56) and smooth muscle cells in human and rabbit atherosclerotic aorta expressed LPL mRNA. O'Brien et al. (17) demonstrated that macrophage-derived foam cells (HAM-56 positive) rather than smooth muscle cells are the primary cellular source of LPL, detected by in situ hybridization, in human coronary plaques. Thus, data are to some extent conflicting and the role of LPL in atherosclerotic tissue is not clarified.

In the present study we analyze the expression of mRNA for lipoprotein lipase and secretion of the enzyme in macrophage (CD14-positive)-derived foam cells from human atherosclerotic tissue at basal levels, as well as the possibility to induce synthesis and secretion.

\section{Methods}

Isolation of cells from tissue. Atherosclerotic aortic tissue was obtained from abdominal aorta $(n=9)$ and femoral arteries $(n=2)$ from patients (age 69-78 yr) undergoing surgery, due to aortic aneurysm or intermittent claudication. The specimens of human atherosclerotic tissue displayed large variation in morphology, with severe atherosclerosis including calcification and thrombosis. After excision, the biopsies were immediately transferred to a $50-\mathrm{ml}$ test tube containing HBSS. Small segments from the tissue specimens were fixed in $4 \%$ paraformaldehyde and paraffin-embedded for histological characterization. The adventitia was removed and intima media preparations were used for cell isolation. Intima media, 0.5-4.1-g tissue wet wt, was minced and

1. Abbreviations used in this paper: FID, flame ionization detection; HMDM, human monocyte-derived macrophages; IM, immunomagnetic; LPL, lipoprotein lipase. 
digested with collagenase solution as previously described (18). Isolated cells were suspended in medium RPMI 1640, supplemented with $1 \%$ BSA, and the cell suspension was kept on a slurry of ice and water after isolation.

This study was approved by the Ethics Committee of Research of the University of Gothenburg, Sweden.

Immunomagnetic (IM) fractionation of macrophages. Macrophages were isolated by using monoclonal antibodies and magnetic microspheres as described (19). Briefly, the heterogeneous cell suspension was preincubated with uncoated dynabeads (Dynal AS, Oslo, Norway) for $10 \mathrm{~min}$ to get rid of collagen and elastin fibers. The cell suspension was then incubated with a mAb, anti-Leu-M3 (BectonDickinson and Co., Sunnyvale, CA ) that recognizes the CD14 antigen present on human macrophages. Anti-HLA-DR and anti-Leukocyte CD45 antibodies were also from (Becton-Dickinson and Co.). The antibodies were dialyzed extensively before use. The rosetting procedure was carried out by mixing pretreated cells with magnetic beads coated with sheep anti-mouse IgG (Dynal AS). The target cells were then isolated by applying a magnet. Rosetted cells were washed several times with PBS, and inspected for the presence of nonrosetted cells by light microscopy. The rosetted isolated cells were quantitated by counting in a hemocytometer and the cell viability was judged by a dye exclusion test with Trypan-blue. A total of $0.4 \times 10^{5}-1.2 \times 10^{6} \mathrm{CD}$ 14-positive cells were recovered per gram tissue, with a cell viability of $74 \pm 15 \%$ (mean \pm SD).

Human monocyte-derived macrophages (HMDM) were obtained by culturing mononuclear cells isolated from buffy coats by the FicollHypaque procedure (20). Mononuclear cells were plated at a density of $10^{7}$ cells/dish. After removal of nonadherent cells the adhered monocytes were cultured in RPMI 1640 supplemented with $100 \mathrm{U} / \mathrm{ml}$ penicillin, $100 \mu \mathrm{g} / \mathrm{ml}$ streptomycin, $10 \% \mathrm{FCS}$, and $10 \%$ human serum. After 6 days the cells were cultured in RPMI 1640 medium with $10 \%$ FCS. The experiments were performed with HMDM $7 \mathrm{~d}$ after plating. The cells were scraped from the petri dish, and the cell number and cell viability were quantitated. When indicated anti-Leu-M3(CD14)-positive cells, CD45-positive cells, and HLA-DR positive cells were isolated from HMDM by the same procedure that was used for digested cells from tissue. Endotoxin levels were analyzed in the reagents and cell culture media using Coatest Endotoxin (Coatech Lab., Ljungby, Sweden ) and were found to be $<0.08 \mathrm{ng} / \mathrm{ml}$.

Preparation and analysis of RNA. Total cellular RNA was isolated from the cells by a micromodification of guanidinium-hydrochloride/ isothiocyanate extraction and $\mathrm{CsCl}$ gradient ultracentrifugation (21). Briefly, cells were lysed with $1 \mathrm{ml}$ of $6 \mathrm{M}$ guanidinium-hydrochloride/ isothiocyanate solution. The cell homogenate was layered on top of 1.2 $\mathrm{ml} 5.7 \mathrm{M} \mathrm{CsCl}$ before centrifugation for $21 \mathrm{~h}$ at $35,000 \mathrm{rpm}$. The following oligonucleotide primers for LPL were synthesized on a DNA synthesizer (Applied Biosystems, Inc., Foster City, CA) 5'-GAGATTTCTCTGTATGGCACC-3' and 5'-CTGCAAATGAGACACTTTCTC-3'. The 5'-primer spanned the junction of the first two exons and the 3 '-primer spanned the junction of the next two exons for LPL (22). For comparison we also amplified mRNA for IL- $1 \beta$, using the primers described by Wang et al. (23). The 5'-primer was labeled in the 5'-end with ${ }^{32} \mathrm{P}$-gamma-ATP using polynucleotide kinase. RNA was reversed, transcribed together with an internal standard (AW 108) into cDNA, and the cDNA was then amplified by PCR. AW 108 is a synthetic cRNA that contains $5^{\prime}$ primers of 12 target mRNAs followed by the complementary sequences of the $3^{\prime}$ primers. Quantitative analysis was performed using the PCR as described by Wang et al. (23) using a Gene Amp RNA PCR Kit (Perkin-Elmer Cetus Corp. Norwalk, CT). Briefly, the reverse transcription mixture containing $1 \mathrm{ng}$ total cellular RNA from HMDM up to $100 \mathrm{ng}$ total RNA from tissue macrophages corresponding to $5 \times 10^{2}-5 \times 10^{4}$ cells, $1 \times 10^{4}-1 \times 10^{5}$ molecules of AW 108 cRNA, and random hexamer primer were incubated at room temperature for $10 \mathrm{~min}, 42^{\circ} \mathrm{C}$ for $15 \mathrm{~min}$, heated to $99^{\circ} \mathrm{C}$ for $5 \mathrm{~min}$, and then in $5^{\circ} \mathrm{C}$ for $5 \mathrm{~min}$. After reverse transcription, serial $1: 2$ or $1: 3$ dilutions of the cDNA mixture were amplified by using the $3^{\prime}$-primer with the ${ }^{32} \mathrm{P}$-labeled 5'-primer. The PCR amplification protocol in- volved denaturation at $95^{\circ} \mathrm{C}$ for $2 \mathrm{~min}$ in cycle 1 , followed by $95^{\circ} \mathrm{C}$ for $1 \mathrm{~min}$, annealing at $60^{\circ} \mathrm{C}$ for $1 \mathrm{~min}$ and extension at $60^{\circ} \mathrm{C}$ for $7 \mathrm{~min}$ in 35 cycles for the analysis of mRNA for LPL. All incubations were done in a Perkin-Elmer Cetus DNA Thermal Cycler. The PCR products were then separated on a $4 \%$ Nusieve GTG agarose gel (FMC Bioproducts Corp., Rockland, ME). $10 \mu$ l of each PCR reaction mixture was electrophoresed with $10 \mu \mathrm{l}$ from a PCR reaction mixture without a radioactive primer. The electrophoresis was run for more than $5 \mathrm{~h}$ and visualized with ethidium bromide (E. Merck AG Darmstadt, Germany). Appropriate bands were cut out from the gel and melted, and the radioactivity was determined by liquid scintillation counting. The amounts of radioactivity recovered from the excised gel bands were plotted against the template concentrations.

Induction of macrophage differentiation with PMA. The IM isolated cells were resuspended in medium RPMI 1640 containing 10\% FCS and 10 nM PMA (Sigma Chemical Company, St. Louis, MO) and seeded at a density of $10^{5}$ cells/dish. The control incubations were performed in medium containing $0.1 \%$ ethanol, the solvent used to dissolve PMA. The HMDM were washed 3 times with PBS before adding the RPMI medium containing PMA to the cells. Heparin 10 $\mathrm{U} / \mathrm{ml}$ (Löwens, Malmö, Sweden) was added to the cells $30 \mathrm{~min}$ before collecting the medium. To study LPL activity, the medium was immediately frozen and stored at $-70^{\circ} \mathrm{C}$ until the day of assay. No sample was stored longer than $14 \mathrm{~d}$ before assay.

Determination of LPL activity. Heparin-releasable LPL activity was determined according to Nilsson-Ehle et al. (24). In brief, $100 \mu \mathrm{l}$ medium was incubated with $100 \mu \mathrm{l}$ fatty acid-labeled triacylglycerol emulsion, as a substrate, at $37^{\circ} \mathrm{C}$. The substrate with $\left[{ }^{3} \mathrm{H}\right]$ triolein (Department of Medical and Physiological Chemistry, University of Lund, Sweden ) and unlabeled triolein was emulsified with lecithin and contained human fasting serum as a source of apo CII and albumin as a fatty acid acceptor, $\mathrm{pH} 8.0$. After $30 \mathrm{~min}$, released $\left[{ }^{3} \mathrm{H}\right]$ oleic acid was isolated from the acylglycerols by a liquid-liquid partition procedure. Liberated $\left[{ }^{3} \mathrm{H}\right]$ oleic acid in the upper phase was quantified with liquid scintillation. All samples were assayed in duplicate (coefficient of variation $2.2 \%$ ). Lipolytic activity was expressed as milliunits ( $\mathrm{mU}$ ) per $10^{6}$ cells. One $\mathrm{mU}$ of enzyme activity represents the release of $1 \mathrm{nmol}$ of fatty acid/min.

Lipid analyses. Lipids were extracted from the arterial macrophages with hexane/isopropanol (3:2, vol/vol). The sample was applied on a quartz rod coated with silica gel, Chromarod SIII (NewmanHowells, Winchester, Hampshire, UK). Separation of lipids was performed with the use of two sequential solvents: hexane/ethyl ether (9:1 vol/vol), hexane/ethyl ether/acetic acid (72:18:1). After each solvent, FID was used to separate and quantify the lipids. The measurements were performed on Iatroscan TH-10 MK2 (Newman-Howells), and signals were integrated on a Hewlett-Packard computer. Quantification of cholesterol ester, triglycerides, and free cholesterol was made by standard comparison.

\section{Results}

Characterization of tissue macrophages. A photomicrograph of a hematoxylin-eosin stained section from one of the atherosclerotic lesions included in the study is shown in Fig. 1. The aortic tissue show intimal thickening with numerous cells and a central lipid core region. 5 to $34 \%$ of all cells digested from tissue with collagenase were CD14-positive. In two experiments an estimation of $40 \%$ of lesion mononuclear cells were recovered as CD14-positive cells. Most of the CD14-positive cells isolated from atherosclerotic lesion were foam cells, as characterized by their appearance as big round cells with foamy cytoplasm, which stained positively with oil red $O(19)$. The frequency of oil red O-stained $C D$ 14-positive cells was $88 \pm 11 \%$ (mean $\pm \mathrm{SD}, n=8$ ). In separate experiments CD 14-positive cells were isolated from tissues similar to those used for LPL measurements, and were analyzed for the lipid content with a 


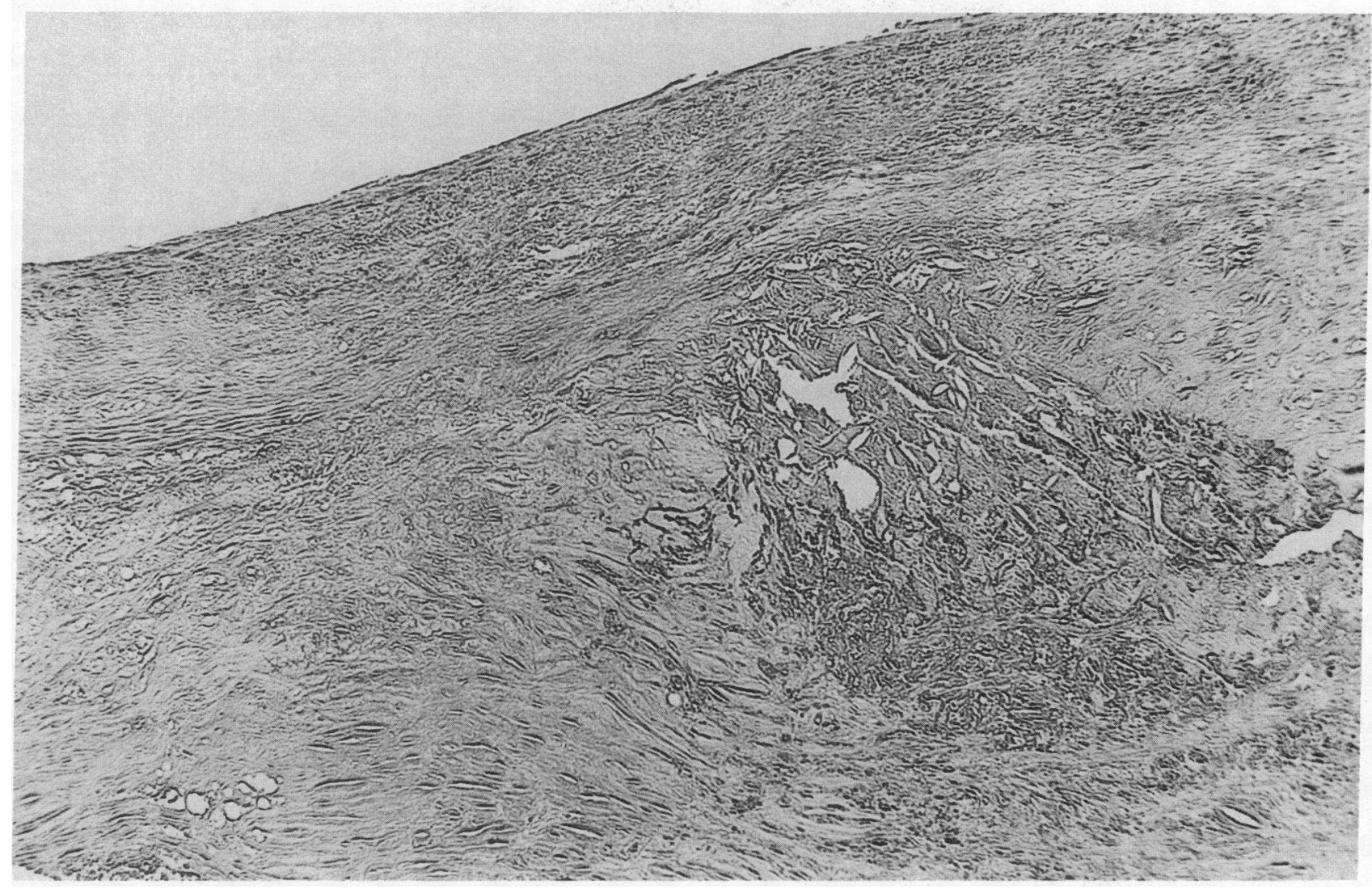

Figure 1. Intima media from one of the analyzed lesions. Tissues were fixed in formaldehyde solution and paraffin-embedded. Hematoxylin/ eosin staining. $\times 50$.

combination of TLC and FID (25). In Table I the concentration of lipids is shown for CD14-positive cells isolated from 11 specimens of human atherosclerotic aorta. The results show accumulation of cholesterol ester, free cholesterol, and triglycerides in these cells.

Preparation and analysis of RNA. To show the expression of mRNA in human cells, RNA was isolated from monocytederived macrophages and from macrophage-derived foam cells (CD 14-positive) from human atherosclerotic tissue. After reverse transcription, cDNA was amplified by PCR. We have used the AW 108 internal standard to determine the amount of LPL mRNA in these cells. For quantification of mRNA it is of importance that the amplification curves are parallel for the standard and the target mRNA. The efficiency of the amplifi-

Table I. Lipid Distribution in Isolated Cells from Human Atherosclerotic Intima Media

\begin{tabular}{lc}
\hline \multicolumn{1}{c}{ Lipid class } & CD 14-positive cells \\
\hline & $\mu g /$ mg cell protein \\
Cholesterol ester & $408 \pm 349$ \\
Triglycerides & $133 \pm 103$ \\
Free cholesterol & $333 \pm 200$ \\
\hline
\end{tabular}

Values are given as mean $\pm \mathrm{SD}(n=11)$. Lipids were extracted from CD14-positive cells isolated from atherosclerotic tissue and analyzed by a combination of TLC and FID. cation was found to be the same for LPL mRNA and AW108 cRNA. When aliquotes of the cDNA mixture were amplified with increasing number of cycles, the exponential phase of amplification was found to be between 24 and 40 cycles. In the present experiments all samples were amplified for 35 cycles. An example of PCR products of LPL mRNA from macrophages and the internal standard in serial 1:3 dilutions of the cDNA mixture is shown in Fig. 2. Reaction products were resolved by gel electrophoresis and visualized by ethidium bromide staining. The size of the LPL PCR product from AW108 cRNA is $300 \mathrm{bp}$ and can be easily separated from the target mRNA PCR product, which has a size of $277 \mathrm{bp}$, for LPL. The amounts of radioactivity recovered from the excised gel bands were plotted against the template concentrations. As shown in Fig. 3, RNA from 2,000 arterial macrophages and 1,000 molecules of AW108 cRNA gave the same amounts of LPL PCR product, which gives 0.5 molecules of LPL mRNA/cell. The cell number is based on viable cells as judged by trypan blue staining. To study the reproducibility of the quantitation of LPL mRNA, two RNA preparations were analyzed in triplicate, and the coefficient of variation was $7.0 \%$. Separate control experiment in which reverse transcriptase was excluded or in which mRNA was excluded showed no detectable signal. These results show that quantification of LPL mRNA with PCR in isolated cells is specific and reproducible (Fig. 3 ).

Expression of $M R N A$ for LPL in isolated cells. We have analyzed arterial CD14 positive macrophages directly after IM isolation from four different human aortic specimens and the data showed between 0.5-6 LPL mRNA molecules/cell ( Table 


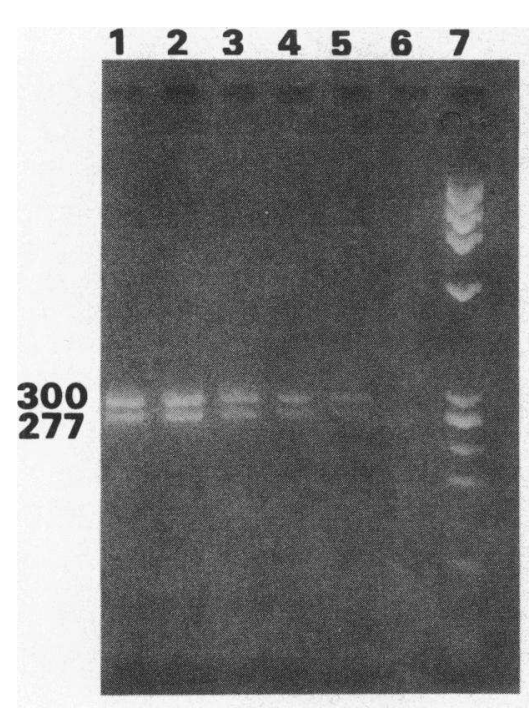

Figure 2. Quantitative analysis of LPL mRNA in macrophages. Ethidium bromide staining of PCR products separated in 4\% agarose gel. Lanes 1-5 indicate LPL mRNA PCR products from $1: 3$ dilutions of a sample containing $1 \mathrm{ng}$ total RNA from macrophages plus $1 \times 10^{5}$ molecules of AW108 cRNA after amplification for 35 cycles. Lane 6 shows the control reaction without template amplified for 35 cycles.

Lane 7 is the molecular weight marker.

II). When blood monocytes attach to petri dishes and differentiate into macrophages, they show a transcriptional activation of mRNA for LPL. The expression of LPL mRNA in the total HMDM population cultured for $7 \mathrm{~d}$ was $\sim 1,600$ molecules/ cell. To study the CD14-positive subpopulation of HMDM, RNA from Leu-M3-positive cells was isolated from HMDM cultured for $7 \mathrm{~d}$. Low levels of LPL mRNA were detected in the Leu-M3-positive macrophages (Table II). It is unlikely that the difference is due to RNA degradation, since the cells were treated in parallel and stored on ice for the same time. When total RNA was run on agarose gel, the preparations showed the same patterns. A difference in viability between total HMDM and CD14-positive cells may exaggerate the difference, since only $70 \%$ of total HMDM were viable while $\sim 90 \%$ of CD14 positive cells were viable. In order to exclude the possibility that collagenase treatment of the cells decreases the levels of LPL mRNA, control experiments were performed in which

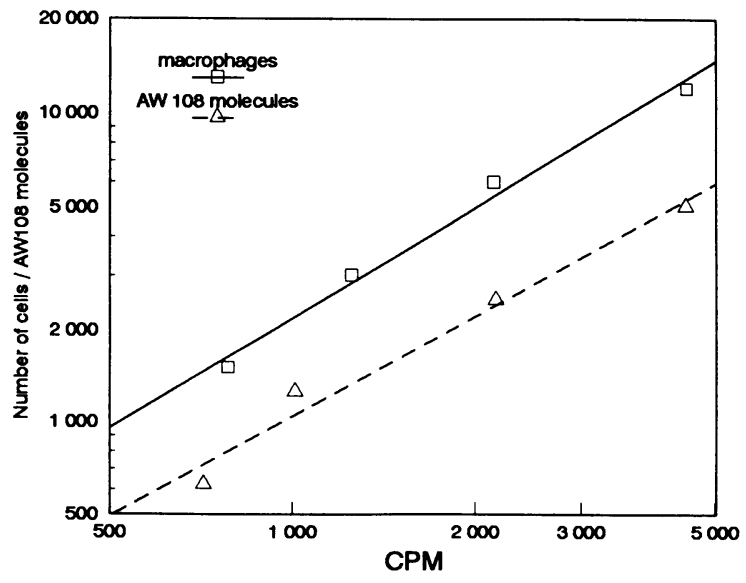

Figure 3. Quantitative analysis of LPL mRNA levels in macrophages isolated from human atherosclerotic aorta. After separation of the PCR products with agarose gel electrophoresis the bands were cut out and radioactivity was determined by liquid scintillation counting. The variable template concentrations of the internal standard AW 108 cRNA $(\Delta)$ and the number of macrophages $(\square)$ were plotted against the radioactivity of their PCR products.
Table II. LPL MRNA Levels in Arterial Macrophages and Human Monocyte-derived Macrophages

\begin{tabular}{lc}
\hline \multicolumn{1}{c}{ Cells } & LPL mRNA \\
\hline & molecules/cell \\
Arterial M. CD14 & $3.4 \pm 2.6$ \\
HMDM & $1,578 \pm 695$ \\
HMDM CD14 & $33 \pm 44$ \\
\hline
\end{tabular}

Total RNA was isolated from macrophage-derived foam cells isolated from atherosclerotic tissue (arterial M. CD14), HMDM cultured for $7 \mathrm{~d}$, and Leu-M3 positive cells isolated from HMDM (HMDM CD14). LPL mRNA molecules/cell is based on viable cells as judged by trypan blue staining. Data represent mean value \pm SD of four experiments.

HMDM were treated with collagenase solution. After incubation with collagenase, the expression of LPL mRNA was 554 LPL mRNA molecules/cell, compared to 496 molecules/cell in the nontreated cells. Another experiment was performed to determine if binding of anti-Leu-M3 antibodies to the CD14 antigen decreases the LPL mRNA expression in HMDM. No difference was found in LPL mRNA levels between cells incubated with anti-Leu-M3 and the control cells. Thus, the cell isolation procedure did not seem to decrease the expression of LPL mRNA.

Induction of LPL $M R N A$ and LPL activity by PMA. To examine if the downregulated expression of LPL $m R N A$ in the arterial macrophages was reversible, the induction of LPL production with PMA was studied. PMA have been shown to modulate differentiation of macrophages and increase LPL secretion (14). LPL mRNA levels were quantitated after culturing of the IM isolated cells with PMA. In one experiment, arterial macrophages were incubated for $6 \mathrm{~h}$ with PMA. No change was observed in mRNA levels, 0.4 LPL mRNA molecules/cell vs. 0.2 LPL mRNA molecules/cell in the controls, without PMA. After $12 \mathrm{~h}$ of incubation with PMA, the mRNA levels were 0.3 LPL mRNA molecules/cell, compared to 0.1 molecules/cell without PMA $(n=2)$. When incubating arterial macrophages with PMA for $24 \mathrm{~h}$, we could not detect any increase in LPL mRNA levels as compared to control cultures, for which 1.0 and 1.6 LPL mRNA molecules/cell were obtained, respectively (Table III). To evaluate the effect of PMA in cultured monocyte-derived macrophages, RNA was isolated after induction of cells with PMA. Induction of LPL mRNA expression appeared after $6 \mathrm{~h}$ incubation of HMDM with PMA. After $12 \mathrm{~h}$ of incubation with PMA the LPL expression reached a maximum, 10,937 LPL mRNA molecules/cell as compared to 675 molecules/cell without PMA (mean value, $n=2$ ). In five experiments a 24-h treatment of the HMDM with PMA increased the levels of LPL mRNA almost twofold (Table III). In one experiment, we isolated CD14, CD45 and HLA-DR positive cells from the same HMDM. LPL mRNA levels were nine times higher in CD 45-positive cells and 6.5 times higher in HLA-DR positive cells compared with CD 14-positive cells (Table IV). This suggests that macrophages that express the CD 14 antigen are a subpopulation of cells that express lower levels of LPL mRNA. To evaluate if culturing of cells with beads changed LPL expression, the CD14, CD45, and HLADR positive cells were cultured with or without PMA for $24 \mathrm{~h}$, after which LPL mRNA expression was measured. The beads 
Table III. LPL MRNA Levels (Molecules/Cell) in PMA-induced and Noninduced Arterial Macrophages and in Monocyte-derived Macrophages

\begin{tabular}{lcc}
\hline \multicolumn{1}{c}{ Cells } & -PMA & +PMA \\
\hline Arterial M. CD14 & 1.6 & 1 \\
HMDM & $1,093 \pm 623$ & $1,940 \pm 671$ \\
HMDM CD14 & 18 & 192 \\
\hline
\end{tabular}

The arterial macrophages (Arterial M), HMDM, and leu-M3 positive cells isolated from HMDM (HMDM CD14) were grown in either the presence or absence of $10 \mathrm{nM}$ PMA for $24 \mathrm{~h}$ before RNA extraction and quantification with PCR. LPL mRNA molecules/cell is based on viable cells as judged by trypan blue staining. Data represent mean value of two experiments from arterial macrophages, and of five experiments from HMDM (mean \pm SD), and mean value of two experiments from HMDM CD14.

were still present and attached to the cells during the culture experiments. Culturing with beads increased the LPL mRNA. The LPL mRNA expression in CD14-positive cells increased from 31 to 328 LPL mRNA molecules per cell after incubation with PMA (Table IV). These results strongly suggest that the mRNA for LPL in macrophages isolated from human atherosclerotic aorta could not be induced with PMA, while a 10-fold increase in mRNA was seen in CD14-positive HMDM. To rule out that the failure of tissue macrophages to respond to PMA was due to collagenase treatment, control experiments were performed in which HMDM were treated with collagenase before immunomagnetic isolation and induction with PMA. A 24-h treatment with PMA showed a ninefold increase of the LPL mRNA expression in the CD14-positive cells, compared with collagenase-treated cells not exposed to PMA. Thus, the ability of CD14-positive cells to respond to PMA was not affected by collagenase treatment.

We also explored the secretion of LPL from CD14-positive foam cells and HMDM. For that purpose, cells were cultured 6, 12 , and $24 \mathrm{~h}$ with or without PMA, heparin was added, and the medium was collected and assayed for the heparin-releasable LPL activity. As shown in Table V, no detectable induction of LPL activity was seen in arterial macrophages. Low activity was seen in arterial macrophages after 6-h and after 12-h stimu-

Table IV. LPL mRNA Levels (Molecules/Cell) in PMA-induced and Noninduced Subpopulations of Monocyte-derived Macrophages

\begin{tabular}{lrrr}
\hline & $0 \mathrm{~h}$ & $24 \mathrm{~h}$ & $24 \mathrm{~h}$ \\
\cline { 2 - 4 } Cells & & -PMA & +PMA \\
\hline CD14 & 13 & 31 & 328 \\
CD45 & 107 & 197 & 236 \\
HLA-DR & 88 & 151 & 244 \\
\hline
\end{tabular}

Total RNA was analyzed in CD14, CD45, and HLA-DR positive cells after isolation from HMDM cultured for $7 \mathrm{~d}$. The CD14, CD45, and HLA-DR positive cells isolated from HMDM were grown in either presence or absence of $10 \mathrm{nM}$ PMA for $24 \mathrm{~h}$ before RNA extraction and quantification with PCR. LPL mRNA molecules/cell is based on viable cells as judged by trypan blue staining.
Table V. LPL Activity in PMA-induced and Noninduced Macrophages

\begin{tabular}{cccccc}
\hline & \multicolumn{2}{c}{ Arterial CD14 } & & \multicolumn{2}{c}{ HMDM } \\
\cline { 2 - 3 } \cline { 5 - 6 } $\begin{array}{c}\text { Incubation } \\
\text { time }\end{array}$ & $-\mathrm{PMA}$ & $+\mathrm{PMA}$ & & $-\mathrm{PMA}$ & $+\mathrm{PMA}$ \\
\hline $6 \mathrm{~h}$ & 0.05 & 0.02 & & 0.86 & 0.66 \\
$12 \mathrm{~h}$ & 0.02 & 0.04 & & 0.72 & 2.68 \\
$24 \mathrm{~h}$ & $0.06 \pm 0.06$ & $0.05 \pm 0.03$ & & $1.14 \pm 0.23$ & $2.94 \pm 0.13$
\end{tabular}

The effect of PMA on the LPL activity in the culture media of macrophage-derived foam cells isolated from atherosclerotic tissue (arterial CD14) and 7-d-old HMDM. Cells were grown for 6, 12, or $24 \mathrm{~h}$ in the presence or absence of $10 \mathrm{nM}$ PMA. Heparin $10 \mathrm{U} / \mathrm{ml}$ was added $30 \mathrm{~min}$ before collecting the media. LPL activity was measured in the medium and is expressed as $\mathrm{mU} / 10^{6}$ cells. The data from $24-\mathrm{h}$ incubation represent the mean value of six experiments from tissue macrophages and of three experiments from HMDM. The other time points are mean values of two experiments.

lation with $10 \mathrm{nM}$ of PMA. We found that the LPL activity was $0.05 \mathrm{mU} / 10^{6}$ cells for foam cells after $24 \mathrm{~h}$ of incubation in the presence of PMA, and the controls without PMA showed 0.06 $\mathrm{mU} / 10^{6}$. For comparison, in HMDM no difference in LPL activity was seen after 6-h incubation with PMA; however, the LPL activity was 40-fold higher than in arterial macrophages. A 3.5-fold increase was detected after $12 \mathrm{~h}$ of incubation with PMA. In HMDM, the LPL activity increased from 1.14 to 2.94 $\mathrm{mU} / 10^{6}$ cells after a 24 -h treatment with $10 \mathrm{nM}$ PMA.

In conclusion, the data are consistent with the observed low levels of LPL mRNA in CD14-positive arterial macrophages. LPL activity was low in noninduced as well as in induced cells. In HMDM, treatment with PMA for $24 \mathrm{~h}$ resulted in $\sim 2.5$ fold increase in LPL activity.

\section{Discussion}

In this study we show that CD14-positive macrophage-derived foam cells isolated from human atherosclerotic aorta express very low levels of mRNA for LPL, and the lipolytic activity of secreted LPL is extremely low. The observations on tissue-derived cells were compared with studies on HMDM. These data suggest that within the blood monocyte population CD14-positive cells may represent a subpopulation with lower expression of LPL. However, even in these cells the expression of LPL mRNA was about tenfold higher than that for tissue-derived cells. Furthermore, the CD14-positive HMDM could be induced to about a 10-fold increase in LPL mRNA after incubation with PMA. These observations suggest that the low level of LPL mRNA and the lack of response to PMA is not due to downregulation or degradation of mRNA during the isolation procedure or during co-culture with magnetic beads (but does not rule it out). Stray et al. (26) have shown that treatment with actinomycin D for $2 \mathrm{~h}$ did not change LPL synthesis, and after $24 \mathrm{~h}$ only a partial inhibition was observed, suggesting that the mRNA for LPL had a rather long half-life. This suggests that the low level of mRNA and the low synthesis found in macrophages isolated from atherosclerotic tissue, is in agreement with other studies in which LPL could not be detected, or was detected in low amounts, in CD14-positive macrophages in human atherosclerotic lesions (15). The isolation procedure 
is based on the expression of CD14. The expression of CD14 antigen is restricted to cells capable of phagocytosis, whereas CD14-negative cells have the ability to mediate extracellular cytolysis without exhibiting any phagocytosing activity (27). This is a subpopulation of the macrophages present in atherosclerotic tissue and it is possible that other subgroups express LPL at higher levels, as shown for CD45-positive or HLA-DR positive cells. The data from in situ hybridizations done by Ylä-Herttuala (16), showing that $10-20 \%$ of macrophages in human lesions express LPL, and data from O'Brien et al. (17), who found that LPL mRNA is associated with the most lipidladen cells of human coronary plaques, suggest that LPL is expressed by a subpopulation of cells. The discrepancy between our results and those of Ylä-Herttuala et al. (16) and O'Brien et al. (17) could be explained by differences involved in not using the same macrophage antibody for detection.

Several factors may be responsible for a downregulation of LPL expression in macrophages, for example bacterial LPS and cytokines such as TNF, IFN- $\gamma$, and IL-1 (28-30). The regulation of LPL by cytokines is complex, depending on the cell system that is used. Treatment with LPS lowered both LPL activity and LPL mRNA in HMDM, but TNF had no effect (28). However, mouse peritoneal macrophages were shown to respond to TNF with a reduction in LPL activity (29). In heart cell cultures the suppression of LPL activity by LPS was mediated by TNF (30). Querfeld et al. (31) have shown that IFN$\gamma$ and IL-1 inhibit production of LPL by HMDM. IL-1 suppresses LPL activity, but not expression of LPL mRNA in rat heart cells (32). We have not found any studies in the literature about the effect of IL-1 on the expression of LPL mRNA in macrophages. Activated macrophages produce TNF and IL-1, but only IL-1 has been shown to reduce LPL activity in HMDM. We have detected mRNA for IL-1 in macrophages isolated from human lesions (not shown). IFN is an activator of macrophages. Jonasson et al. (33) have demonstrated that IFN- $\gamma$ suppressed synthesis and secretion of LPL by macrophages at IFN doses that upregulated expression of the activation marker HLA-DR. We have in earlier studies showed that most of the isolated macrophage-derived foam cells also expressed HLA-DR (19). Activated T lymphocytes are present in the atherosclerotic plaque, and activated $T$ cells produce IFN- $\gamma$ (for review see reference 34). In human macrophages, treatment with IFN reduced LPL mRNA along with medium LPL activity, suggesting that the inhibitory effects occur at the level of transcription or mRNA stabilization (30). Therefore, the downregulation of LPL in arterial macrophages may be explained by a local production of IFN and IL-1 in the lesion.

Addition of PMA to cells had an augmenting effect on LPL secretion by macrophages in vitro $(14,34)$. This is in agreement with our results. When monocyte-derived macrophages as well as CD14-positive HMDM were incubated with PMA, the LPL mRNA expression was increased. In contrast, PMA had no effect on CD14-positive macrophages isolated from atherosclerotic aorta; no change was observed in LPL mRNA levels or in LPL activity. It has been observed that the LPL expression increased when monocytes differentiate into macrophages, and when promonocytic cell lines, such as THP-1 cells, are stimulated by phorbol esters (35), suggesting that LPL expression is linked to the differentiation, rather than to activation of the cells. Because differentiated cells express high LPL activity in vitro, and mature and quiescent cells show suppressed activity $(13,14)$, it might be speculated that newly recruited monocytes in growing plaques express high levels of LPL, and that the activity is later suppressed as the cells become foam cells. It has recently been shown by Sofer et al. (36) that accumulation of triglycerides decreased the LPL secretion in a dose-dependent manner in macrophages. It is possible that the suppressed LPL expression found in this study is due to triglyceride accumulation, since CD14-positive cells from human aorta contained high levels of triglycerides as well as free cholesterol and cholesterol ester. Further investigation will be required to assess the role of LPL expression in lipid loaded macrophages, and in macrophages in different states of activation in human atherosclerotic tissue.

In conclusion, these studies show a very low expression of LPL mRNA in the CD14-positive macrophage-derived foam cells isolated from human atherosclerotic tissue. The low LPL activity or the expression of LPL mRNA could not be induced with PMA to the levels found in HMDM. These data suggest that the CD14-positive cells are a subpopulation of foam cells that express low levels of lipoprotein lipase, and the cell lipid content could be a major factor for downregulation of LPL.

\section{Acknowledgments}

We thank the Drs. Kent Lundholm and Folke Nilsson at the Departments of Surgery and Thoracic Surgery and Dr. Bo Risberg and Peter Falk at Östra Hospital for providing us with human arterial tissue.

This study was supported by grants from the Swedish Heart-Lung Foundation, the Medical Research Council, and the Medical Faculty of Gothenburg.

\section{References}

1. Fowler, S., H. Shio, and N. J. Haley. 1979. Characterization of lipid-laden aortic cells from cholesterol-fed rabbits. IV. Investigation of macrophage-like properties of aortic cell populations. Lab. Invest. 41:372-378.

2. Gianturco, S. H., W. A. Bradley, A. M. Gotto, Jr., J. D. Morrisett, and D. L. Peavy. 1982. Hypertriglyceridemic very low density lipoproteins induce triglyceride synthesis and accumulation in mouse peritoneal macrophages. J. Clin. Invest. 70:168-178.

3. Kraemer, F. B., Y-D. I. Chen, R. D. Lopez, and G. M. Reaven. 1983. Characterization of the binding site on thioglycolate-stimulated mouse peritoneal macrophages that mediates the uptake of very low density lipoproteins. J. Biol. Chem. 258:12190-12197.

4. Steinberg, D., S. Parthasarathy, T. E. Carew, J. C. Khoo, and J. L. Witztum 1989. Beyond cholesterol. Modifications of low-density lipoprotein that increase its atherogenicity. N. Engl. J. Med. 14:915-924.

5. DiCorleto, P. E., and D. B. Zilversmit. 1975. Lipoprotein lipase activity in bovine aorta. Proc. Soc. Exp. Biol. Med. 148:1101-1105.

6. Corey, J. E., and D. B. Zilversmit. 1977. Effect of cholesterol feeding on arterial lipolytic activity in the rabbit. Atherosclerosis. 27:201-212.

7. Lindqvist, P., A-M. Östlund-Lindqvist, J. L. Witztum, D. Steinberg, and J. A. Little. 1983. The role of lipoprotein lipase in the metabolism of triglyceriderich lipoproteins by macrophages. J. Biol. Chem. 258:9086-9092.

8. Aviram, M., E. L. Bierman, and A. Chait. 1988. Modification of low density lipoprotein by lipoprotein lipase or hepatic lipase induces enhanced uptake and cholesterol accumulation in cells. J. Biol. Chem. 263:15416-15422.

9. Beisiegel, U., W. Weber, and G. Bengtsson-Olivecrona. 1991. Lipoprotein lipase enhances the binding of chylomicrons to low density lipoprotein receptorrelated protein. Proc. Natl. Acad. Sci. USA. 88:8342-8346.

10. Mahoney, E. M., J. C. Khoo, and D. Steinberg. 1982. Lipoprotein lipase secretion by human monocytes and rabbit alveolar macrophages in culture. Proc. Natl. Acad. Sci. USA. 79:1639-1642.

11. Khoo, J. C., E. M. Mahoney, and J. L. Witztum. 1981. Secretion of lipoprotein lipase by macrophages in culture. J. Biol. Chem. 256:7105-7108.

12. Behr, S. R., and F. B. Kraemer. 1986. Regulation of the secretion of lipoprotein lipase by mouse macrophages. Biochim. Biophys. Acta. 889:346-354.

13. Goldman, R., and O. Sopher. 1989. Control of lipoprotein lipase secretion in mouse macrophages. Biochim. Biophys. Acta. 1001:120-126.

14. Goldman, R. 1990. Control of lipoprotein lipase secretion by macrophages: effect of macrophage differentiation agents. J. Leukocyte. Biol. 47:79-86. 
15. Jonasson, L., G. Bondjers, and G. K. Hansson. 1987. Lipoprotein lipase in atherosclerosis: its presence in smooth muscle cells and absence from macrophages. J. Lipid. Res. 28:437-445.

16. Ylä-Herttuala, S., B. A. Lipton, M. E. Rosenfeld, I. J. Goldberg, D. Steinberg, and J. L. Witztum. 1991. Macrophages and smooth muscle cells express lipoprotein lipase in human and rabbit atherosclerotic lesions. Proc. Natl. Acad. Sci. USA. 88:10143-10147.

17. O'Brien, K. D., D. Gordon, S. Deeb, M. Ferguson, and A. Chait. 1992. Lipoprotein lipase is synthesized by macrophage-derived foam cells in human coronary atherosclerotic plaques. J. Clin. Invest. 89:1544-1550.

18. Wiklund, O., L. Mattsson, T. Björnheden, G. Camejo, and G. Bondjers. 1991. Uptake and degradation of low density lipoproteins in atherosclerotic rabbit aorta: the role of local modification. J. Lipid. Res. 32:55-62.

19. Mattsson, L., G. Bondjers, and O. Wiklund. 1991. Isolation of cell populations from arterial tissue, using monoclonal antibodies and magnetic microspheres. Atherosclerosis. 89:25-34.

20. Böyum, A. 1976. Isolation of lymphocytes, granulocytes and macrophages. Scand. J. Immunol. 5(Suppl 5):9.

21. Chirgwin, J. M., A. M. Przybyla, R. J. MacDonald, and W. J. Rutter. 1979. Isolation of biologically active ribonucleic acid from sources enriched in ribonuclease. Biochemistry. 18:5294-5298.

22. Wion, K. L., T. G. Kirchgessner, A. J. Lusis, M. C. Schotz, and R. M. Lawn. 1987. Human lipoprotein lipase complementary DNA sequence. Science (Wash. DC). 235:1638-1641.

23. Wang, A. M., M. V. Doyle, and D. F. Mark. 1989. Quantification of mRNA by the polymerase chain reaction. Proc. Natl. Acad. Sci. USA. 86:97179721.

24. Nilsson-Ehle, P., H. Törnqvist, and P. Belfrage. 1972. Rapid determination of lipoprotein lipase activity in human adipose tissue. Clin. Chim. Acta. 42:383-390.

25. Bondjers, G., T. Linden, G. Fager, S-O. Olofsson, G. Olsson, and O. Wiklund. 1988. Aortic intimal lipid content and serum lipoproteins in patients undergoing coronary by-pass surgery as related to clinical prognosis. Atherosclero sis. 72:231-239.

26. Stray, N., H. Letnes, and J. P. Blomhoff. 1990. Intracellular regulation of lipoprotein lipase in human monocyte-derived macrophages. Biochim. Biophys. Acta. 1045:280-284.

27. Gidlund, M., P. Rossi, P. Cotran, U. Ramstedt, and H. Wigzell. 1988. In human monocytes a strong correlation exists between expression of the M3 antigen, Fc-mediated phagocytic activity and failure to participate in extracellular antibody-dependent cytotoxicity. Eur. J. Immunol. 18:477-480.

28. White, J. R., A. Chait, S. J. Klebanoff, S. Deeb, and J. D. Brunzell. 1988. Bacterial lipopolysaccaride reduces macrophage lipoprotein lipase levels: an ef fect that is independent of tumor necrosis factor. J. Lipid Res. 29:1379-1385.

29. Friedman, G., T. Chajek-Shaul, R. Gallily, O. Stein, E. Shiloni, J. Etienne and Y.Stein. 1988. Modulation of lipoprotein lipase activity in mouse peritonea macrophages by recombinant human tumor necrosis factor. Biochim. Biophys. Acta. 963:201-207.

30. Friedman, G., R. Gallily, T. Chajek-Shaul, O. Stein, E. Shiloni, J. Etienne and Y. Stein. 1988. Lipoprotein lipase in heart cell cultures is suppressed by bacterial lipopolysaccaride: an effect mediated by production of tumor necrosis factor. Biochim. Biophys. Acta. 960:220-228.

31. Querfeld, U., J. M. Ong, J. Prehn, J. Carty, B. Saffari, S. C. Jordan, and P. A. Kern. 1990. Effects of cytokines on the production of lipoprotein lipase in cultured human macrophages. J. Lipid Res. 31:1379-1386.

32. Friedman, G., V. Barak, T. Chajek-Shaul, J. Etienne, A. J. Treves, O. Stein, and Y. Stein. 1991. Recombinant human interleukin-1 suppresses lipoprotein lipase activity, but not expression of lipoprotein lipase mRNA in mesenchymal rat heart cell cultures. Biochim. Biophys. Acta. 1089:83-87.

33. Jonasson, L., G. K. Hansson, G. Bondjers, L. Noe, and J. Etienne. 1990. Interferon-gamma inhibits lipoprotein lipase in human monocyte-derived macrophages. Biochim. Biophys. Acta. 1053:43-48.

34. Hansson, G. K., L. Jonasson, P. S. Seifert, and S. Stemme. 1989. Immune mechanisms in atherosclerosis. Arteriosclerosis. 9:567-578.

35. Auwerx, J. H., S. Deeb, J. D. Brunzell, R. Peng, and A. Chait. 1988. Transcriptional activation of the lipoprotein lipase and apolipoprotein $\mathrm{E}$ genes accompanies differentiation in some human macrophage-like cell lines. Biochemistry. 27:2651-2655.

36. Sofer, O., M. Fainaru, Z. Schafer, and R. Goldman. 1992. Regulation of lipoprotein lipase secretion in murine macrophages during foam cell formation in vitro. Arterioscler. Thromb. $12 \cdot 1458-1466$. 